\title{
Functional Role of the Noncatalytic Domains of Elongation Factor Tu in the Interactions with Ligands ${ }^{\dagger}$
}

\author{
Rengül Cetin,,$\perp \perp$ Pieter H. Anborgh, $\$, \S$ Robbert H. Cool," and Andrea Parmeggiani*, \\ Groupe de Biophysique-Equipe 2, Ecole Polytechnique, F-91128 Palaiseau Cedex, France, and Abteilung Strukturelle Biologie, \\ Max-Planck-Institut für molekulare Physiologie, D-44026 Dortmund, Germany
}

Received February 26, 1997; Revised Manuscript Received September 30, $1997^{\otimes}$

\begin{abstract}
Elongation factor (EF) Tu from Escherichia coli contains three domains, of which domain 1 (N-terminal domain) harbors the site for nucleotide binding and GTP hydrolysis. To analyze the function of domains 2 [middle $(\mathrm{M})$ domain] and 3 [C-terminal $(\mathrm{C})$ domain], EF-Tu( $\Delta \mathrm{M})$ and $\mathrm{EF}-\mathrm{Tu}(\Delta \mathrm{C})$ were engineered as GST-fused products and purified. Circular dichroism and thermostability showed that both constructs have conserved organized structures. Though inactive in poly(Phe) synthesis the two constructs could bind GDP and GTP with comparable micromolar affinities. Therefore, like the isolated N-terminal domain, they had lost a typical feature of EF-Tu, the $>100$ times stronger affinity for GDP than for GTP. $\mathrm{EF}-\mathrm{Tu}(\Delta \mathrm{M})$ and EF-Tu( $\Delta \mathrm{C})$ had an intrinsic GTPase activity comparable to that of wild-type EF-Tu. Ribosomes did not stimulate the GTPase activity of either factor, while kirromycin increased the GTPase activity of both constructs, particularly of EF-Tu( $\Delta C)$, to a level, however, much lower than that of the intact molecule. The interaction with aa-tRNA of both mutants was $>90 \%$ reduced. As a major result, their GDP-bound form could efficiently respond to EF-Ts. All four EF-Tu-specific antibiotics [kirromycin, pulvomycin, GE2270 A (=MDL 62 879), and enacyloxin IIa] retarded significantly the dissociation of EF-Tu $(\Delta C) \cdot G T P$, showing the same kind of effect as on EF-Tu GTP, but they were little active on EF$\mathrm{Tu}(\Delta \mathrm{M}) \cdot \mathrm{GTP}$. Like EF-Tu( $(\Delta \mathrm{C}) \cdot \mathrm{GTP}, \mathrm{EF}-\mathrm{Tu}(\Delta \mathrm{M}) \cdot \mathrm{GTP}$ was, however, able to bind efficiently kirromycin and enacyloxin IIa, as determined via competition with EF-Ts. Together, these results enlight selective functions of domains 2 and 3, particularly toward the interaction with EF-Ts and antibiotics, and emphasize their functional cooperativity for an efficient interaction of EF-Tu with ribosomes and aa-tRNA and for maintaining the differential affinity for GTP and GDP.
\end{abstract}

In bacterial protein biosynthesis, the GTP-bound elongation factor $\mathrm{Tu}(\mathrm{EF}-\mathrm{Tu})^{1}$ acts as the carrier of aa-tRNA to the mRNA-programmed ribosome (Miller \& Weissbach, 1977; Kaziro, 1978; Weijland et al., 1992). The recycling

$\doteqdot$ This work was carried out in the framework of Contract ERBCHRXCT 940510 (Program Human Capital and Mobility of the E. C.) and was suported by grants from the Ligue Nationale Française Contre le Cancer, Fédération National des Centres de Lutte Contre le Cancer, and Association pour la Recherche sur le Cancer (no. 6377). R.C. was the recipient of a Fellowship of the Ministère des Affaires Estrangères and P.H.A. of the Fondation pour la Recherche Médicale.

* Corresponding author. Tel: x33-169334180. Fax: x33-169334840. E-mail: andrea@poly.polytechnique.fr.

Ecole Polytechnique.

${ }^{\perp}$ Present address: Faculty of Science, Department of Molecular Biology and Genetics, Bilkent University, TR-06533 Bilkent, Ankara, Turkey.

$\S$ Present address: Laboratory of Cellular Oncology, National Cancer Institute, Bethesda, MD 20892.

"Max-Panck-Institut für molecular Physiologie, D-44026 Dortmund, Germany.

${ }^{\otimes}$ Abstract published in Advance ACS Abstracts, December 1, 1997.

${ }^{1}$ Abbreviations: EF-Tu, GST-fused elongation factor Tu from Escherichia coli; EF-Ts and EF-G, elongation factors Ts and G; G domain, EF-Tu lacking residues 203-392; EF-Tu( $\Delta$ C), GST-fused EFTu lacking residues $301-392 ; \mathrm{EF}-\mathrm{Tu}(\Delta \mathrm{M})$, GST-fused EF-Tu lacking residues 205-294; GST, glutathione S-transferase; ME, 2-mercaptoethanol; DDT, dithiothreitol; PMFS, phenylmethane sulfonyl fluoride; $\mathrm{PK}$, pyruvate kinase; PEP, phosphoenolpyruvate; $\mathrm{CD}$, circular dichroism; $t_{50}$, temperature for half-maximum activity; $3 \mathrm{D}$, three dimensional; IPTG, isopropyl $\beta$-D-thiogalactopyranoside. of EF-Tu•GTP requires two events: the hydrolysis of GTP, leading to the GDP-bound state with low affinity for aatRNA and ribosomes, and the exchange of bound GDP and free GTP, a reaction accelerated by EF-Ts. EF-Tu is the target of four families of antibiotics: kirromycin, pulvomycin, GE2270 A [for references, see Parmeggiani and Swart (1985) and Anborgh and Parmeggiani (1991)], and enacyloxin IIa (Cetin et al., 1996). Kirromycin prevents the dissociation of EF-Tu-GDP from the ribosome-aa-tRNA complex; GE2270 A and pulvomycin inhibit the interaction between EF-Tu·GTP and aa-tRNA, and enacyloxin IIa hinders the incorporation of aa-tRNA into polypeptidyl-tRNA by acting on both EF-Tu and the ribosome.

Recently, the progress of our knowledge of the tertiary structure of EF-Tu has helped in clarifying several aspects of the interactions between EF-Tu and its ligands. X-ray diffraction studies (Kjeldgaard \& Nyborg, 1992; Berchtold et al., 1993; Kjeldgaard et al., 1993, Polekhina et al., 1996; Abel et al., 1996) have revealed marked differences in the orientations of the EF-Tu domains - particularly of domains 2 and 3 toward domain 1-depending on whether GDP or GTP is bound. Moreover, they have shown that the binding of aa-tRNA to EF-Tu-GTP takes place in the interfaces between domains 1 and 2 and domains 2 and 3 (Nissen et al., 1995) and that the EF-Tu•EF-Ts complex has the major contact on domain 1 (Kawashima et al., 1996). 
Site-directed mutagenesis has largely contributed to enlighten the structural-functional background of the EF-Tu interactions. In particular, point substitutions in and around the nucleotide binding pocket have outlined the properties of this region [for references, see Weijland et al. (1992)]. Concerning the functional role of the three domains, the isolated domain 1 ( $\mathrm{G}$ domain) of Escherichia coli $\mathrm{EF}-\mathrm{Tu}$ was found to bind the nucleotide (Parmeggiani et al., 1987; Jensen et al., 1989) and catalyze the hydrolysis of GTP, but its activities were no longer exposed to regulatory constrains induced by the various ligands. This suggested that domains 2 and 3 modulate the EF-Tu interaction with ligands. These observations encouraged us to apply the mutagenic approach to define the functions of the two noncatalytic domains. In this work, we report on the characterization of two E. coli EF-Tu constructs lacking either domain $2[\mathrm{EF}-\mathrm{Tu}) \Delta \mathrm{M})]$ or domain $3[\mathrm{EF}-\mathrm{Tu}(\Delta \mathrm{C})]$ and, in particular, on their role in the interaction with ligands.

\section{MATERIALS AND METHODS}

Materials. Restriction enzymes, T4 DNA ligase, and calf intestinal alkaline phosphate were from Boehringer, Mannheim; glutathione-Sepharose 4B was from Pharmacia-LKB; human thrombin and reduced glutathione were from Sigma Chemical Co. (St. Louis, MO). For other biological materials see Parmeggiani and Sander (1981). Kirromycin, pulvomycin, and GE2270 A (=MDL 62 879) were used as described (Anborgh \& Parmeggiani, 1991, 1993). Enacyloxin IIa, obtained from Dr. K. Izaki (Tohoku University, Sendai, Miyagi 982, Japan), was kept as a $10 \mathrm{mM}$ stock solution in $100 \%$ methanol at $-20{ }^{\circ} \mathrm{C}$ (Cetin et al., 1996).

Construction, Production, and Purification of Deleted EF$T u$ 's. Site-directed mutagenesis was carried out on the $E$. coli tufA gene cloned in pEMBL9 ${ }^{+}$, using synthetic oligodeoxynucleotides (Parmeggiani et al., 1987). For constructing EF-Tu( $\Delta \mathrm{C}), 5^{\prime}$-C ATC AAG $\mathrm{CCG}_{\Delta}$ GGC TAA TTG CA-3' was used as mutagenic primer. Its $5^{\prime}$-half hybridized to nucleotides 891-900 of tufA and its $3^{\prime}$-half to nucleotides 1177-1187, comprising the C-terminal Gly393, the termination codon, and five nucleotides of the C-terminal flanking region. With this primer we could loop out the nucleotides encoding His301 to Leu392, a region of the molecule including the $\mathrm{C}$-terminal domain of EF-Tu. For constructing $\operatorname{EF}-\mathrm{Tu}(\Delta \mathrm{M})$, the $5^{\prime}$-half of the mutagenic primer $5^{\prime}$-A GAG CGT GCG $\triangle$ AAG CCG GGC A-3' was hybridized to nucleotides 608-615 and its 3'-half to nucleotides 880-891, looping out the nucleotides encoding Ile206 to Ala293 and thus the middle domain. Both constructs were checked by DNA sequence. The $M_{\mathrm{r}}$ 's of the two constructs are 32907 $[\operatorname{EF}-\mathrm{Tu}(\Delta \mathrm{C})$ and $33483[\mathrm{EF}-\mathrm{Tu}(\Delta \mathrm{M})]$.

To prepare the GST fusions, the coding sequence of tufA (or its deleted mutants) was inserted into the unique BamHI site of pGEX-2T, under control of the IPTG-inducible tac promoter (Smith \& Johnson, 1988). The BamHI site was engineered upstream to the $5^{\prime}$-end of the first codon of tufA, resulting in the in-frame fusion of the GST and tufA gene. Preserved at the fusion junction was the site for endoproteolytic cleavage by thrombin (Leu-Val-Pro-Arg $\downarrow$ Gly-Ser). Since the Ser residue in this sequence corresponds to the N-terminal Ser of EF-Tu, after cleavage the resulting EFTu contains an additional N-terminal Gly. SDS-PAGE of the crude cell extracts showed overproduction of a protein with a $M_{\mathrm{r}}$ of $\sim 70000$, which corresponds to the expected relative molecular mass for the GST-fused EF-Tu $\left(M_{\mathrm{r}}=\right.$ $26000+43000$ ), or of a protein with a $M_{\mathrm{r}}$ of $\sim 60000$ in the case of both fused mutants $\left(M_{\mathrm{r}}=26000+33000\right)$.

For purification of the various EF-Tu forms, E. coli cells $(10 \mathrm{~g})$ were resuspended in $50 \mathrm{~mL}$ of buffer $\mathrm{A}(50 \mathrm{mM}$ Tris$\mathrm{HCl}, \mathrm{pH} 7.6,60 \mathrm{mM} \mathrm{KCl}, 5 \mathrm{mM} \mathrm{MgCl} 2,10 \mu \mathrm{M}$ GDP, and $7 \mathrm{mM}$ ME) containing $1 \mathrm{mM}$ PMSF and sonicated on ice. After centrifugation ( $30000 \mathrm{~g}$ for $30 \mathrm{~min}$ ), the supernatant was applied to a prepacked glutathione-Sepharose 4B column ( $2 \mathrm{~mL})$, preequilibrated with buffer A. After a wash with $20 \mathrm{~mL}$ of the same buffer, the elution was carried out with $10 \mathrm{~mL}$ of buffer A, containing $5 \mathrm{mM}$ reduced glutathione. The next step was on an Ultrogel AcA44 column $(100 \mathrm{~cm} \times 3 \mathrm{~cm})$, preequilibrated and eluted with buffer A. To cleave GST, thrombin $(1 \mu \mathrm{M} / \mathrm{mL})$ in buffer A plus 2.5 $\mathrm{mM} \mathrm{CaCl} 2$ was slowly passed on the GST-fused EF-Tu bound to the affinity column at $4{ }^{\circ} \mathrm{C}$ (flow rate: $0.5 \mathrm{~mL} /$ $\min )$. The action of thrombin was stopped with $0.2 \mathrm{mM}$ PMSF.

Circular Dichroism Measurements. The circular dichroism (CD) spectra of the various GST-fused products were measured with a Jasco 710 spectropolarimeter (Japan Spectroscopic Co., Ltd., Tokyo) in a $0.1 \mathrm{~cm}$ cuvette at room temperature and at a concentration of $0.15 \mathrm{mg}$ of protein/

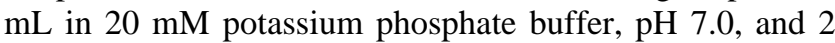
$\mathrm{mM} \mathrm{MgCl} 2$. Since the proteins were diluted at least 10fold in the phosphate buffer, the remaining storage buffer components $(<1 \mathrm{mM} \mathrm{ME}$ and $<5 \%$ glycerol) did not interfere with $\mathrm{CD}$ measurements. Ten spectra were taken for each protein and subsequently averaged. The mean residue ellipticity $[\theta]_{\mathrm{m}}$ was calculated from the ellipticity $(\theta)$ by the equation $[\theta]_{\mathrm{m}}=(\theta) /(n c)$, where $n$ indicates the number of peptide bonds in the protein and $c$ the molar concentration of the protein.

Other Methods. For DNA sequencing by the dideoxy chain-termination method, Sequenase 2.0 (USB) was used. Plasmid purification, agarose gel electrophoresis, and DNA transformation were performed by standard methods (Sambrook et al., 1990). Poly(Phe) synthesis (Jacquet \& Parmeggiani, 1988), GDP or GTP dissociation rates and dissociation constants (Fasano et al., 1978; Parmeggiani et al., 1987; Anborgh et al., 1993), spontaneous hydrolysis of PhetRNA $^{\text {Phe }}$ (Cetin et al., 1996), equilibrium dialysis (Créchet \& Parmeggiani, 1986), and EF-Tu-dependent binding to poly $(\mathrm{U}) \cdot$ ribosomes and native PAGE (Anborgh \& Parmeggiani, 1991) were carried out as described. Hydrolysis of $\left[\gamma-{ }^{32} \mathrm{P}\right] \mathrm{GTP}$ was measured according to the charcoal method (Ivell et al, 1981) and the complex between Phe-tRNA ${ }^{\text {Phe }}$ and the GTP-bound EF-Tu forms by filtration on Sephadex G25 columns $(0.37 \times 15 \mathrm{~cm})$ (Créchet \& Parmeggiani, 1986). In the experiments involving GTP, it was carefully controlled that the presence of trace contaminations of nucleotidases did not influence the reactions by affecting critically the concentration of GTP. When needed, an excess of ATP was added to damp down unspecific nucleotidase activities. The standard buffer we referred to in the legends to the figures was $50 \mathrm{mM}$ Tris- $\mathrm{HCl}, \mathrm{pH} 7.6,60 \mathrm{mM} \mathrm{NH}_{4} \mathrm{Cl}$, $10 \mathrm{mM} \mathrm{MgCl}_{2}$, and $1 \mathrm{mM}$ DTT. The G-domain, the isolated $\mathrm{N}$-terminal domain of EF-Tu, was purified according to Parmeggiani et al. (1987) and Jensen et al. (1989). Protein 


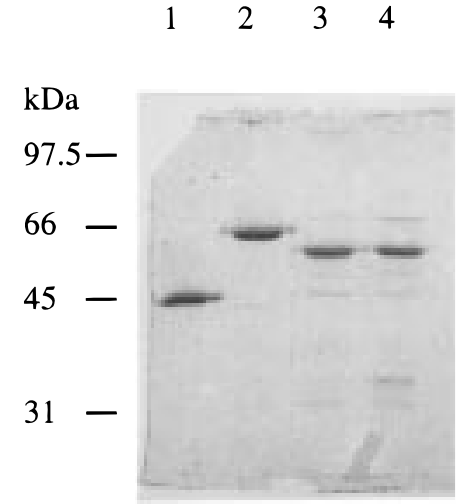

FIGURE 1: SDS-PAGE patterns of unfused EF-Tu, GST-fused EF$\mathrm{Tu}, \mathrm{EF}-\mathrm{Tu}(\Delta \mathrm{C})$, and $\mathrm{EF}-\mathrm{Tu}(\Delta \mathrm{M})$ after purification by GST affinity and AcA44 gel filtration chromatography. Protein bands were visualized by staining with Coomassie Brilliant Blue. Of each protein, $1 \mu \mathrm{g}$ was applied. Lanes: (1) unfused EF-Tu; (2) fused EF-Tu; (3) EF-Tu( $\Delta \mathrm{C})$; (4) $\operatorname{EF}-\mathrm{Tu}(\Delta \mathrm{M})$.

concentration was determined by the method of Bradford (1976), using bovine serum albumin as standard.

\section{RESULTS}

Production of EF-Tu( $\Delta C)$ and $E F-T u(\Delta M)$. Maximum production of the recombinant protein was obtained after 3 $\mathrm{h}$ of induction at $30{ }^{\circ} \mathrm{C}$ or $7 \mathrm{~h}$ at $24{ }^{\circ} \mathrm{C}$ in the presence of $0.1-0.3 \mathrm{mM}$ IPTG. In the cell extract, $\mathrm{EF}-\mathrm{Tu}(\Delta \mathrm{C})$ and EF$\mathrm{Tu}(\Delta \mathrm{M})$ were $30-40 \%$ soluble, while EF-Tu was $>80 \%$ soluble. In the case of EF-Tu( $(\Delta M)$, it was important to keep the induction temperature at $24^{\circ} \mathrm{C}$. After affinity chromatography, $\mathrm{EF}-\mathrm{Tu}(\Delta \mathrm{C})$ or $\mathrm{EF}-\mathrm{Tu}(\Delta \mathrm{M})$ were $\sim 80 \%$ pure, as tested on SDS-PAGE. The yield was $\sim 85 \%$ of the initial soluble product, i.e., $2-3.5 \mathrm{mg} / \mathrm{g}$ of induced cells at $2.0 A_{600}$. As shown in Figure 1, passage on Ultrogel AcA44 increased the purification of EF-Tu( $\Delta \mathrm{C})$ (lane 3 ) and $\mathrm{EF}-\mathrm{Tu}(\Delta \mathrm{M})$ (lane 4) to $\sim 90 \%$ and of EF-Tu (lane 2) to $\sim 100 \%$. GST could be cleaved by thrombin digestion; unfortunately, release of GST made the mutated proteins more prone to aggregation, reducing markedly the yield. Therefore, since the presence of GST did not appear to influence much the majority of the EF-Tu activities, the mutated forms were used in most experiments as GST fusions, unless otherwise stated, taking GST-fused GlyEF-Tu as reference.

Circular Dichroism and Stability to Heat Denaturation. In order to verify the influence of the deletion of domain 2 or 3 on the tertiary structure, the CD spectra of the two mutated forms fused with GST were compared to the spectra of GST-EF-Tu (Figure 2). As a first result, each product showed a CD spectrum of a protein with a defined structure. Furthermore, the percentage of $\alpha$-helical stretches was larger in the two deletion mutants $(208-222 \mathrm{~nm})$, whereas the signal around $203 \mathrm{~nm}$, indicative for the $\beta$-strand content, was smaller in the mutants, as compared to the full-length protein. These differences are to be expected since deletion of the middle or of the C-terminal domain removes parts of EF-Tu that contain only $\beta$-strands. The spectrum of EF$\mathrm{Tu}(\Delta \mathrm{C})$ bears strong resemblance to that reported for the corresponding construct [EF-Tu(I, II)] from Thermus thermophilus (Nock et al., 1995).

Concerning the resistance to heat denaturation (Figure 3), inactivation of GDP-bound $\mathrm{EF}-\mathrm{Tu}(\Delta \mathrm{C})$ and $\mathrm{G}$ domain

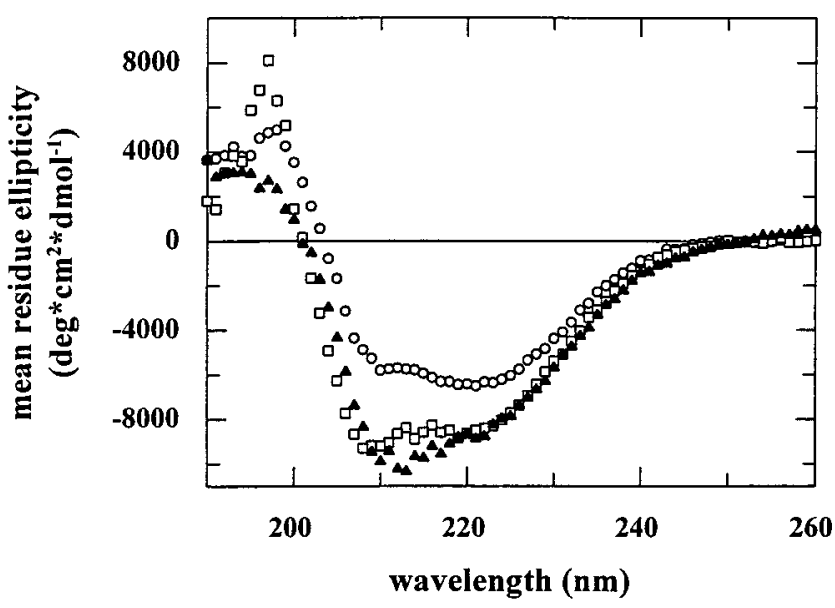

FIGURE 2: Circular dichroism of the various forms of EF-Tu: CD signal of $0.15 \mathrm{mg} / \mathrm{mL}$ GDP-bound GST-fused products [EF-Tu $(O)$, $\operatorname{EF}-\mathrm{Tu}(\Delta \mathrm{C})(\boldsymbol{\Delta})$, and $\mathrm{EF}-\mathrm{Tu}(\Delta \mathrm{M})(\square)]$ in $20 \mathrm{mM}$ potassium phosphate buffer, $\mathrm{pH} 7.0$, and $2 \mathrm{mM} \mathrm{MgCl} 2$ at room temperature after determination of the molar residual ellipticity, $[\theta]_{\mathrm{m}}$.

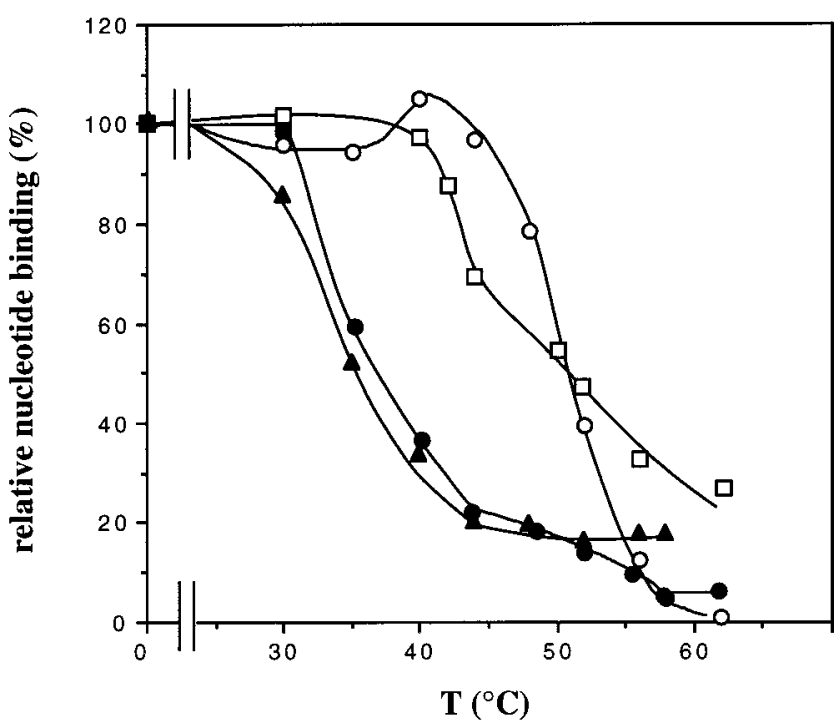

FIGURE 3: Temperature-induced denaturation of EF-Tu, EF-Tu$(\Delta \mathrm{C})$, EF-Tu $(\Delta \mathrm{M})$, and $\mathrm{G}$ domain. Twenty picomoles of GDPbound EF-Tu $(O), \operatorname{EF}-\mathrm{Tu}(\Delta \mathrm{C})(\mathbf{\Delta}), \operatorname{EF}-\mathrm{Tu}(\Delta \mathrm{M})(\square)$, or $\mathrm{G}$ domain $\cdot$ GDP (๑), preincubated for $15 \mathrm{~min}$ at $30^{\circ} \mathrm{C}$ in $20 \mu \mathrm{L}$ of standard buffer in the presence of $140 \mathrm{pmol}$ of $\left[{ }^{3} \mathrm{H}\right] \mathrm{GDP}$ (specific activity, $3100 \mathrm{dpm} / \mathrm{pmol}$ ), was incubated for $8 \mathrm{~min}$ at the indicated temperatures, cooled on ice, and then spotted on nitrocellulose filters. The results are expressed as a percentage of the $\left[{ }^{3} \mathrm{H}\right] \mathrm{GDP}$ binding obtained upon incubation for $8 \mathrm{~min}$ at $0{ }^{\circ} \mathrm{C}$.

occurred at lower temperature than that of the full-length molecule $\left(t_{50}=37\right.$ vs $\left.51^{\circ} \mathrm{C}\right)$. $\operatorname{EF}-\mathrm{Tu}(\Delta \mathrm{M}) \cdot \mathrm{GDP}\left(t_{50}=51\right.$ $\left.{ }^{\circ} \mathrm{C}\right)$ was less stable than full-length EF-Tu between 42 and $51{ }^{\circ} \mathrm{C}$ and more stable at $>52{ }^{\circ} \mathrm{C}$. The border course of inactivation of the mutated forms suggests a more pronounced conformational heterogeneity than in the case of EF-Tu.

EF-Tu( $\Delta C)$ and EF-Tu( $\Delta M)$ Are Inactive in Poly(Phe) Synthesis. GST-fused EF-Tu, though much less active in poly(Phe) synthesis than unfused EF-Tu, showed a significant activity $(\sim 10 \%$ that of native EF-Tu or of thrombin cleaved GlyEF-Tu, not shown). The presence of an additional glycine at the N-terminus of EF-Tu was irrelevant for the rate of poly(Phe) synthesis or any other activity of EF-Tu. $\mathrm{EF}-\mathrm{Tu}(\Delta \mathrm{C})$ and $\mathrm{EF}-\mathrm{Tu}(\Delta \mathrm{M})$ were totally inactive in poly- 


\begin{tabular}{|c|c|c|c|c|}
\hline system & $\begin{array}{l}\text { dissociation half-life } \\
(\mathrm{min})\end{array}$ & $\begin{array}{c}\text { dissociation rate constant } \\
10^{4} k_{-1}\left(\mathrm{~s}^{-1}\right)\end{array}$ & $\begin{array}{c}\text { association rate constant } \\
10^{-4} k_{+1}\left(\mathrm{~s}^{-1} \mathrm{M}^{-1}\right)\end{array}$ & $\begin{array}{c}\text { dissociation constant } \\
K_{\mathrm{d}}(\mu \mathrm{M}) \\
\end{array}$ \\
\hline $\mathrm{EF}-\mathrm{Tu} \cdot \mathrm{GTP}$ & 0.8 & 138 & 6.9 & 0.2 \\
\hline $\mathrm{GST}-\mathrm{EF}-\mathrm{Tu} \cdot \mathrm{GTP}$ & 1.6 & 72 & 0.8 & 0.9 \\
\hline GST-EF-Tu $(\Delta C) \cdot$ GTP & 2 & 58 & 0.097 & 6 \\
\hline $\mathrm{GST}-\mathrm{EF}-\mathrm{Tu}(\Delta \mathrm{M}) \cdot \mathrm{GTP}$ & 9 & 12.8 & 0.013 & 10 \\
\hline $\mathrm{G}$ domain $\cdot \mathrm{GTP}$ & 1 & 115 & 0.18 & $6.2^{b}$ \\
\hline EF-Tu $\cdot G D P$ & 80 & 1.4 & 7.2 & 0.002 \\
\hline $\mathrm{GST}-\mathrm{EF}-\mathrm{Tu} \cdot \mathrm{GDP}$ & 68 & 1.7 & 8.5 & 0.002 \\
\hline GST $-\mathrm{EF}-\mathrm{Tu}(\Delta \mathrm{C}) \cdot \mathrm{GDP}$ & 12 & 9.6 & 0.046 & 2.1 \\
\hline GST-EF-Tu $(\Delta M) \cdot G D P$ & 20 & 5.8 & 0.019 & 3 \\
\hline $\mathrm{G}$ domain $\cdot \mathrm{GDP}$ & 4 & 29 & 0.13 & $2.1^{b}$ \\
\hline
\end{tabular}

${ }^{a}$ Determined at $0{ }^{\circ} \mathrm{C}$. Association rate constants were determined as $k_{+1}=k_{-1} / K_{\mathrm{d} .}{ }^{b}$ Taken from Jensen et al. (1989).

(Phe) synthesis, even after cleavage of GST by thrombin (not shown).

The Affinity for GDP Is the Most Affected Parameter in the Guanine Nucleotide Interaction of Mutated EF-Tu's. The presence of GST did not essentially modify the nucleotide interaction of full-length EF-Tu [Table 1; $c f$. also Fasano et al. (1978) and Scarano et al. (1995)]. A typical property of EF-Tu is its 2 orders of magnitude higher affinity for GDP than for GTP. An important modification of the two mutated forms is that the affinities for GDP and GTP both lie in the micromolar range, a property also observed with the $G$ domain (Parmeggiani et al., 1987; Jensen et al., (1989). The $K_{\mathrm{d}}$ value of the GDP complex of EF-Tu( $\left.\Delta \mathrm{C}\right)$ and EF-Tu$(\Delta \mathrm{M})$ has thus increased 3 orders of magnitude $v$ s that of the full-length EF-Tu, whereas the $K_{\mathrm{d}}$ of the GTP complex has only increased 1 order of magnitude. Noteworthy, the GDP off-rates of EF-Tu( $(\Delta \mathrm{C}) \cdot \mathrm{GDP}$ and $\mathrm{EF}-\mathrm{Tu}(\Delta \mathrm{M}) \cdot \mathrm{GDP}$, though faster than the off-rate of EF-Tu-GDP, are severalfold slower than that of the $\mathrm{G}$ domain-GDP.

EF-Tu $(\Delta C)$ and EF-Tu( $\Delta M)$ Can Still Express an Intrinsic GTPase Activity. Effect of Kirromycin and Ribosomes. EF$\mathrm{Tu}$ is endowed with a very low intrinsic GTPase activity that can be specifically enhanced by ribosomes or kirromycin (Fasano et al., 1982). In studying the GTPase activity of the two mutated EF-Tu's, we observed the presence of trace contaminations of nucleotidases (GTPases/ATPases), even in our most purified preparations, especially with EF-Tu$(\Delta \mathrm{M})$. Considering the very low activity of the intrinsic GTP hydrolysis of EF-Tu (Fasano et al., 1982), it was important to neutralize this unspecific activity. Since the nucleotide binding to EF-Tu is strictly specific for the guanine base, as shown by 3D analysis (Jurnak, 1985, Kjeldgaard \& Nyborg, 1992), we damped down the nucleotidase activity by adding to our assay (i) high concentrations of $\mathrm{KCl}$ that, besides increasing the intrinsic GTPase activity of EF-Tu (Fasano et al., 1978; Ivell et al., 1981) or G domain (Jensen et al., 1989), strongly inhibit nucleotidase activities (A. Parmeggiani, unpublished results) and (ii) high concentrations of ATP. Moreover, we also tested the GTPase activity in the presence of kirromycin, whose action is known to enhance selectively the EF-Tu-dependent GTPase. The results show that the GTPase activity, determined at concentrations of GTP corresponding to a 50\% saturation of wild-type EF-Tu and the two mutated constructs, yields comparable values, that of EF-Tu( $\Delta \mathrm{C})$ being somewhat lower (Figure 4). The presence of $50 \mu \mathrm{M}$ kirromycin enhanced the activity of wild type $\sim 8$ times, that of EF-Tu( $\Delta \mathrm{C}) \sim 2$ times, and that of $\operatorname{EF}-\mathrm{Tu}(\Delta \mathrm{M}) \sim 30 \%$.

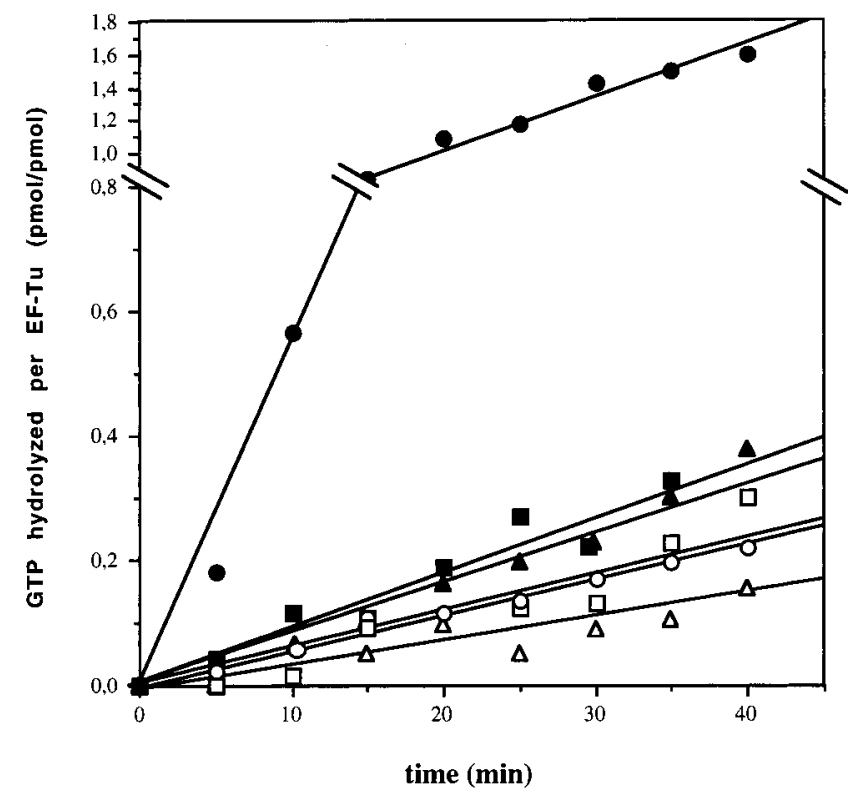

FIGURE 4: Intrinsic GTPase activity of EF-Tu, EF-Tu( $\Delta C)$, and $\operatorname{EF}-\mathrm{Tu}(\Delta \mathrm{M})$ and effect of kirromycin. Reaction mixtures $(200 \mu \mathrm{L})$ containing $50 \mathrm{mM}$ imidazolium acetate, $\mathrm{pH} 7.5,2 \mathrm{M} \mathrm{KCl}, 10 \mathrm{mM}$ $\mathrm{MgCl}_{2}, 1 \mathrm{mM}$ DTT, $2 \mathrm{mM}$ PEP, $40 \mu \mathrm{g} / \mathrm{mL}$ PK, $200 \mu \mathrm{M}$ ATP, and $1 \mu \mathrm{M}$ EF-Tu (circles), EF-Tu( $\Delta \mathrm{C})$ (triangles), or $\mathrm{EF}-\mathrm{Tu}(\Delta \mathrm{M})$ (squares) were incubated for $20 \mathrm{~min}$ at $30{ }^{\circ} \mathrm{C}$. After a further 5 min incubation without (open symbols) or with (closed symbols) $50 \mu \mathrm{M}$ kirromycin at $30^{\circ} \mathrm{C}$, the reaction preceded by addition of $0.9,6$, and $10 \mu \mathrm{M}\left[\gamma_{-}{ }^{32} \mathrm{P}\right] \mathrm{GTP}$ for EF-Tu, EF-Tu( $\left.\Delta \mathrm{C}\right)$, and EF$\mathrm{Tu}(\Delta \mathrm{M})$, respectively (specific activity, $1500 \mathrm{dpm} / \mathrm{pmol})$. At the indicated times, aliquots $(20 \mu \mathrm{L})$ were withdrawn and the liberated $\left[\gamma-{ }^{32} \mathrm{P}\right] \mathrm{P}_{\mathrm{i}}$ was determined.

Unprogrammed ribosomes that efficiently stimulate the intrinsic GTPase activity of full-length EF-Tu, whether fused or unfused, and also slightly enhance the intrinsic GTPase of the G domain (Jensen et al., 1989) were inactive on both EF-Tu mutants (not shown).

The Removal of Either One of the Noncatalytic Domains Strongly Weakens the Interaction with aa-tRNA. The ability of the EF-Tu mutants to interact with aa-tRNA was determined by (i) formation of a stable complex, (ii) protection against spontaneous deacylation of aa-tRNA, and (iii) binding of aa-tRNA to poly(U)-programmed ribosomes. Since the half-life of the EF-Tu-GTP complex is strongly increased ( $>100$ times) by the presence of aa-tRNA, the stability of this interaction was determined by following the migration of $\left[\gamma-{ }^{32} \mathrm{P}\right] \mathrm{GTP}$ on Sephadex G25 gel filtration columns (Créchet \& Parmeggiani, 1986). As shown in Figure $5 \mathrm{~A}$, in the presence of Val-tRNA ${ }^{\mathrm{Val}}$ the EF-Tu $[\gamma$ - 


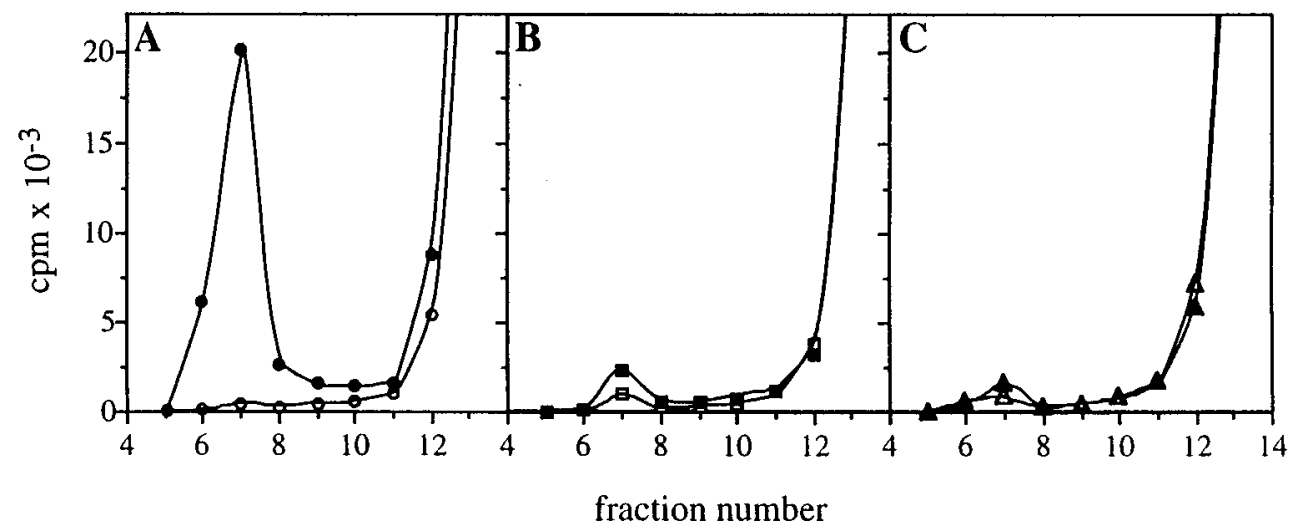

FIGURE 5: Formation of a stable complex between Val-tRNA ${ }^{\mathrm{Val}}$ and EF-Tu, EF-Tu $(\Delta \mathrm{C})$, or EF-Tu $(\Delta \mathrm{M})$. The reaction mixtures contained, in $30 \mu \mathrm{L}$ of standard buffer, $1 \mu \mathrm{M}$ EF-Tu(A), EF-Tu( $\Delta \mathrm{M})(\mathrm{B})$, or EF-Tu( $\Delta \mathrm{C})(\mathrm{C}), 5 \mu \mathrm{M}\left[\gamma^{3}{ }^{32} \mathrm{P}\right] \mathrm{GTP}$ (specific activity, $3500 \mathrm{dpm} / \mathrm{pmol}$ ), $1 \mathrm{mM}$ PEP, and $40 \mu \mathrm{g} / \mathrm{mL} \mathrm{PK}$ incubated at $10 \mathrm{~min}$ at $30^{\circ} \mathrm{C}$ in the absence (open symbols) or presence (closed symbols) of $5 \mu \mathrm{M}$ ValtRNA $^{\text {Val }}$ and were subsequently passed onto a Sephadex G25 column $(0.37 \times 15 \mathrm{~cm})$ equilibrated with standard buffer. Fractions $(100 \mu \mathrm{L})$ were collected and the radioactivity was determined.

$\left.{ }^{32} \mathrm{P}\right] \mathrm{GTP}$ formed a discrete peak preceding the free $\left[\gamma_{-}{ }^{32} \mathrm{P}\right]-$ GTP, while in its absence EF-Tu-bound $\left[\gamma-{ }^{32} \mathrm{P}\right] \mathrm{GTP}$ was not detectable. With the mutant EF-Tu's only a small amount of bound $\left[\gamma_{-}{ }^{32} \mathrm{P}\right] \mathrm{GTP}$ preceded the free $\left[\gamma_{-}{ }^{32} \mathrm{P}\right] \mathrm{GTP}$, corresponding to $\sim 9 \%[\mathrm{EF}-\mathrm{Tu}(\Delta \mathrm{M})$, Figure $5 \mathrm{~B}]$ and $\sim 5 \%$ [EF$\mathrm{Tu}(\Delta \mathrm{C})$, Figure $5 \mathrm{C}]$ of that bound to full-length EF-Tu.

In experiments not illustrated, neither EF-Tu( $\Delta \mathrm{M})$ nor EF$\mathrm{Tu}(\Delta \mathrm{C})$ in complex with GTP could influence the rate of the spontaneous deacylation of Phe-tRNA ${ }^{\text {Phe }}$, differently from EF-Tu. This shows that the interaction between the EF-Tu variants and the aminoacylated $3^{\prime}$-end of aa-tRNA is anomalous.

Furthermore, whereas EF-Tu $\cdot$ GTP strongly enhanced the binding of Phe-tRNA ${ }^{\text {Phe }}$ to poly(U) $\cdot$ ribosomes (from about $10 \%$ in its absence to $>90 \%$ ), only a very low $\operatorname{EF}-\mathrm{Tu}(\Delta \mathrm{M})$ or EF-Tu $(\Delta C)$-dependent stimulation of the Phe-tRNA ${ }^{\text {Phe }}$ binding could be detected, corresponding to $5-8 \%$ that induced by EF-Tu·GTP (Figure 6). These results are in agreement with the reduced capability of the deleted EFTu's to form a stable complex with aa-tRNA (see above).

EF-Ts Interacts Efficiently with GDP-Bound EF-Tu( $\Delta C)$ and $E F-T u(\Delta M)$. The action of EF-Ts on the mutant EFTu was determined by measuring the exchange rate of EFTu-bound $\left[{ }^{3} \mathrm{H}\right] \mathrm{GDP}$ or $\left[{ }^{3} \mathrm{H}\right] \mathrm{GTP}$ with the corresponding free unlabeled nucleotide (Figure 7). The addition of EF-Ts (closed symbols with dashed lines) in a 1:100 molar ratio markedly decreased the half-life of EF-Tu $(\Delta \mathrm{C}) \cdot \mathrm{GDP}$ (panel 7B) and $\mathrm{EF}-\mathrm{Tu}(\Delta \mathrm{M}) \cdot \mathrm{GDP}$ (panel $7 \mathrm{C}$ ) to values comparable to those obtained with EF-Tu. If the GDP release was estimated by taking into account the higher $(\sim 2$ times) intrinsic GDP/GDP exchange of the two mutants (Table 1), the effect of EF-Ts on EF-Tu( $(\Delta \mathrm{M})$ was about half and that on EF-Tu( $\Delta C)$ one-third of the stimulation on the control EF-Tu. Addition of more EF-Ts to a 1:1 molar ratio to EFTu further increased the velocity of the dissociation rate without essentially affecting the difference between mutated forms and wild-type factor. EF-Ts did not enhance the dissociation rate of $\mathrm{G}$ domain $\cdot \mathrm{GDP}$, which is intrinsically much faster than that of full-length EF-Tu and also of the two mutated forms.

Remarkably, we were unable to detect any effect of EFTs on the dissociation rate of EF-Tu $(\Delta C) \cdot$ GTP and EF-Tu$(\Delta \mathrm{M}) \cdot \mathrm{GTP}$ even if EF-Ts was added to a 2:1 molar excess (not shown).

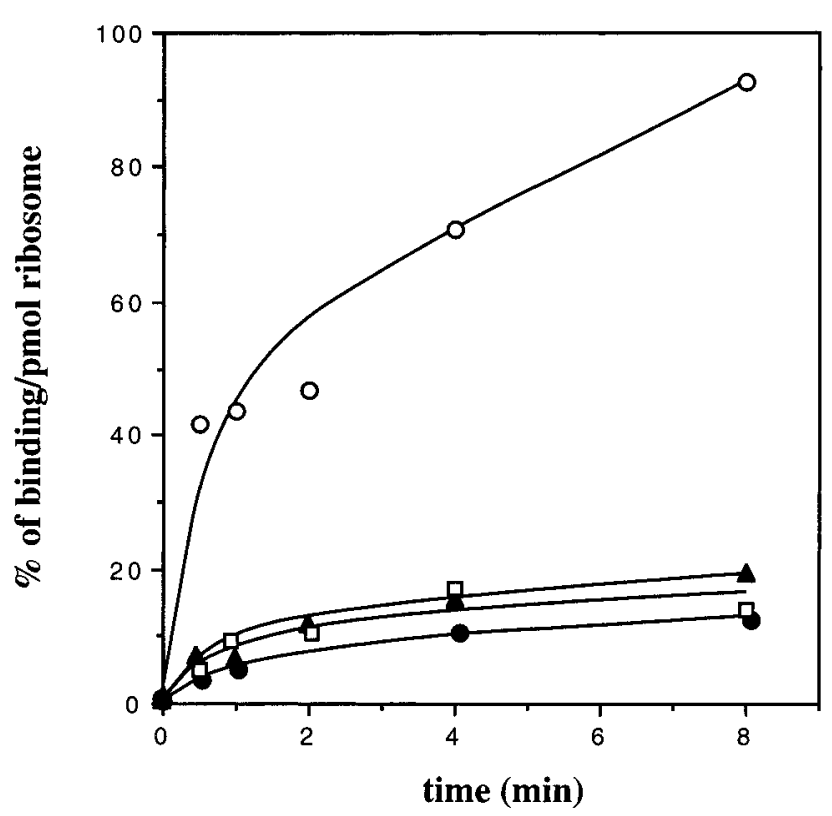

FIGURE 6: Enzymatic binding of $\left[{ }^{14} \mathrm{C}\right] \mathrm{Phe}-\mathrm{tRNA}{ }^{\text {Phe }}$ to the A-site of poly(U)-programmed ribosomes mediated by EF-Tu, EF-Tu$(\Delta \mathrm{C})$, or $\mathrm{EF}-\mathrm{Tu}(\Delta \mathrm{M})$. The reaction mixture $(20 \mu \mathrm{L})$ contained 25 $\mathrm{mM}$ Tris- $\mathrm{HCl}, \mathrm{pH} 7.6,86 \mathrm{mM} \mathrm{NH}_{4} \mathrm{Cl}, 10 \mathrm{mM} \mathrm{MgCl} 2,7 \mathrm{mM} \mathrm{ME}$, $1 \mathrm{mM}$ ATP, $0.25 \mathrm{mM}$ GTP, $1 \mathrm{mM}$ PEP, PK $(40 \mu \mathrm{g} / \mathrm{mL}), 0.5 \mu \mathrm{M}$ ribosomes poly(U) $(80 \mu \mathrm{g} / \mathrm{mL}), 0.5 \mu \mathrm{M}$ tRNA ${ }^{\text {Phe }}, 0.7 \mu \mathrm{M}\left[{ }^{14} \mathrm{C}\right]-$ Phe-tRNA $^{\text {Phe }}$ (specific activity, $584 \mathrm{dpm} / \mathrm{pmol}$ ), and $1 \mu \mathrm{M}$ EF-Tu $(\bigcirc), \operatorname{EF}-\mathrm{Tu}(\Delta \mathrm{C})(\boldsymbol{\Delta}), \operatorname{EF}-\mathrm{Tu}(\Delta \mathrm{M})(\square)$ or no enzyme $(\bullet)$. The diverse EF-Tu's in complex with GTP were preincubated with $\left[{ }^{14} \mathrm{C}[]-\right.$ Phe-tRNA ${ }^{\text {Phe }}$ and the ribosomes with tRNA ${ }^{\text {Phe }}$ and poly(U), for 10 min at $30{ }^{\circ} \mathrm{C}$. The reaction was initiated by the addition of the poly(U)-programmed ribosomes. The binding of $\left[{ }^{14} \mathrm{C}\right] \mathrm{Phe}-\mathrm{tRNA}{ }^{\mathrm{Phe}}$ to the ribosomal A-site was determined by the nitrocellulose binding assay.

EF-Tu-Specific Antibiotics Are Active on GTP-Bound EF$T u(\Delta C)$. A common effect of the action of the EF-Tuspecific antibiotic is the strong retardation of the EF-Tu. GTP dissociation rate (Parmeggiani \& Swart, 1985; Anborgh \& Parmeggiani, 1993; Cetin et al., 1996). Therefore, the dissociation rate of the GTP complex is the most representative parameter for analyzing the response to antibiotics of the mutated EF-Tu's. As shown in Figure 8, kirromycin, pulvomycin, GE2270 A, and enacyloxin IIa were able to retard consistently the dissociation rate of $\mathrm{EF}-\mathrm{Tu}(\Delta \mathrm{C}) \cdot \mathrm{GTP}$ from 4- to 7-fold, depending on the kind of antibiotic. With 


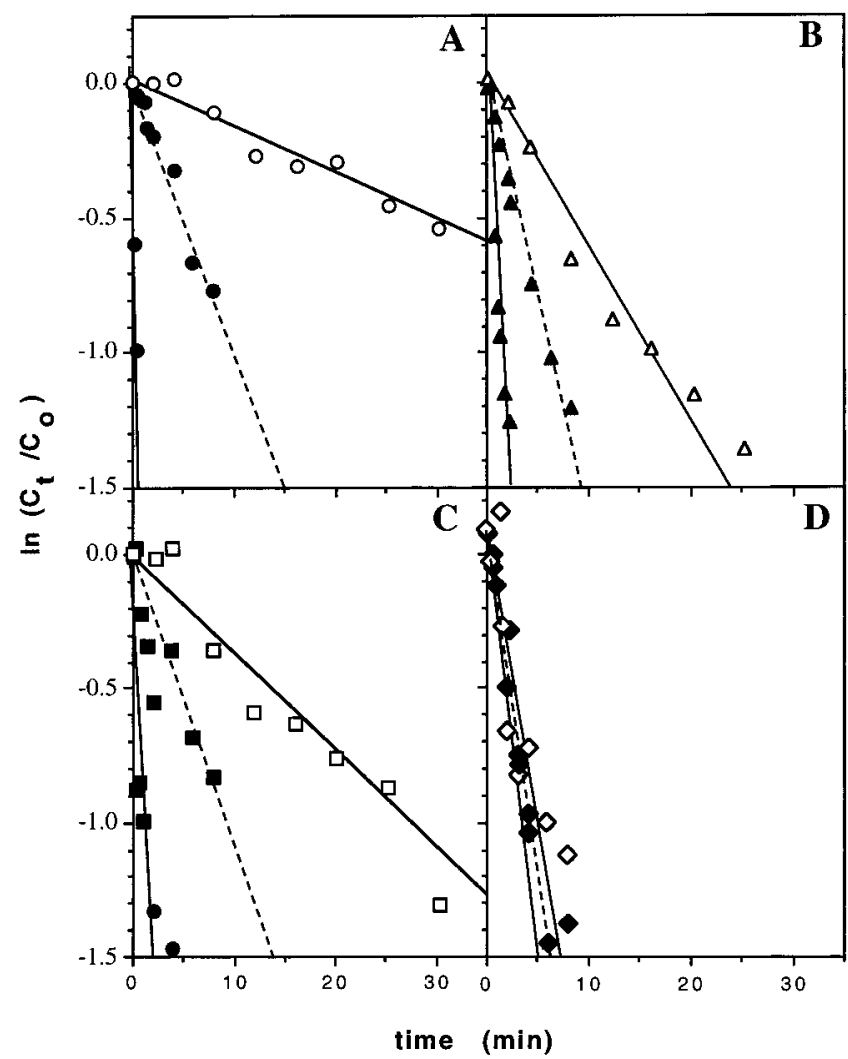

FIGURE 7: Action of EF-Ts on the GDP dissociation rates of EF$\mathrm{Tu}, \operatorname{EF}-\mathrm{Tu}(\Delta \mathrm{C}), \operatorname{EF}-\mathrm{Tu}(\Delta \mathrm{M})$, and $\mathrm{G}$ domain. A $0.5 \mu \mathrm{M}$ quantity of EF-Tu (A), EF-Tu( $\Delta \mathrm{C})(\mathrm{B}), \mathrm{EF}-\mathrm{Tu}(\Delta \mathrm{M})(\mathrm{C})$, or the $\mathrm{G}$ domain (D) was incubated in $400 \mu \mathrm{L}$ of standard buffer containing $2.5 \mu \mathrm{M}$ $\left[{ }^{3} \mathrm{H}\right] \mathrm{GDP}$ (specific activity, $4400 \mathrm{dpm} / \mathrm{pmol}$ ) for $15 \mathrm{~min}$ at $30^{\circ} \mathrm{C}$. After a further incubation for $5 \mathrm{~min}$ at $0{ }^{\circ} \mathrm{C}$ in the absence (open symbols) or in the presence of EF-Ts (closed symbols) at a concentration of either 0.5 (solid line) or $0.005 \mu \mathrm{M}$ (dashed line), the dissociation reaction was started by the addition of a 1000-fold excess of cold GDP at $0{ }^{\circ} \mathrm{C}$. At the indicated times, aliquots $(40$ $\mu \mathrm{L}$ ) were withdrawn, and the EF-Tu-bound radioactivity was determined by the nitrocellulose binding assay. $c_{0}$ represents the initial concentration of the EF-Tu-nucleotide complex and $c_{t}$ the concentration at the time $t$.

enacyloxin IIa, the increase in half-life of $\mathrm{EF}-\mathrm{Tu}(\Delta \mathrm{C}) \cdot \mathrm{GTP}$ was $\sim 50 \%$ that of the control EF-Tu, with kirromycin $\sim 30 \%$, and with pulvomycin and GE2270 A 5-10\% ( $c f$. panel B with A). Much lower was the effect of the antibiotics on $\mathrm{EF}-\mathrm{Tu}(\Delta \mathrm{M})$ (Figure $8 \mathrm{C})$. Enacyloxin IIa retarded it 10 times less than in the case of $\operatorname{EF}-\mathrm{Tu}(\Delta \mathrm{C})$, and with the other three antibiotics the effect was scarcely significant. The half-life of the $\mathrm{G}$ domain $\cdot \mathrm{GTP}$ complex displayed a minimal response, if any (Figure 8D). These results show selective differences between $\operatorname{EF}-\mathrm{Tu}(\Delta \mathrm{C})$ and $\operatorname{EF}-\mathrm{Tu}(\Delta \mathrm{M})$ in the response to antibiotics.

Kirromycin and Enacyloxin IIa Compete with EF-Ts for Binding to $\mathrm{EF}-\mathrm{Tu}(\triangle C)$ and $\mathrm{EF}-\mathrm{Tu}(\Delta M)$ in Complex with $G D P$. It has long been known that EF-Ts and kirromycin compete for binding to EF-Tu. This property has been used to remove this antibiotic from EF-Tu by means of a dialysis of EF-Tu•kirromycin in the presence of EF-Ts (Swart et al., 1987; Anborgh \& Parmeggiani, 1993). Of the other three EF-Tu-specific antibiotics, only enacyloxin IIa can compete with EF-Ts for binding to EF-Tu like kirromycin (Cetin et al., 1996). Therefore, we tested whether EF-Ts and these two antibiotics were still able to compete for binding to the two mutated EF-Tu forms. The experiments illustrated in

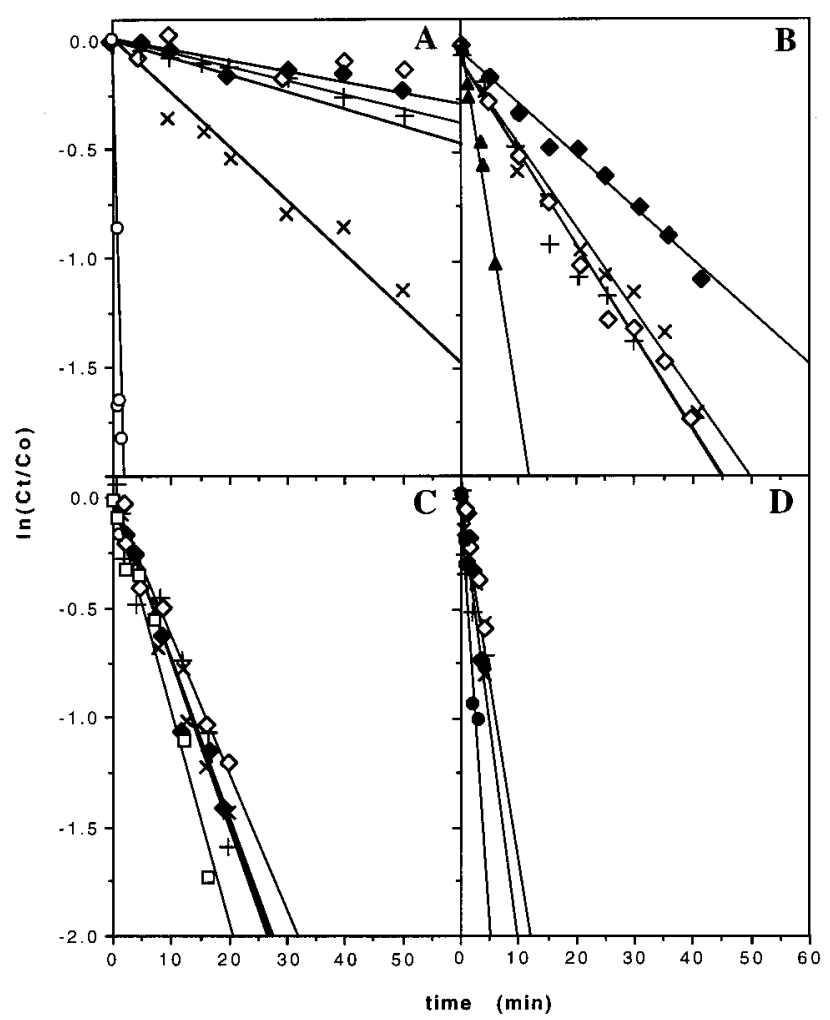

FIGURE 8: Influence of the EF-Tu-specific antibiotics on the dissociation rate of the complex between GTP and EF-Tu, EF-Tu$(\Delta \mathrm{C}), \mathrm{EF}-\mathrm{Tu}(\Delta \mathrm{M})$, or $\mathrm{G}$ domain. The reaction mixture $(400 \mu \mathrm{L}$ of standard buffer) containing $1 \mu \mathrm{M}$ EF-Tu (A), EF-Tu( $\Delta \mathrm{C})(\mathrm{B})$, $\mathrm{EF}-\mathrm{Tu}(\Delta \mathrm{M})(\mathrm{C})$, or $\mathrm{G}$ domain (D), $2.5 \mu \mathrm{M}\left[{ }^{3} \mathrm{H}\right] \mathrm{GTP}$ (specific activity, $12000 \mathrm{dpm} / \mathrm{pmol}$ ), $2.5 \mathrm{mM}$ ATP, $1 \mathrm{mM}$ PEP, $40 \mu \mathrm{g} / \mathrm{mL}$ $\mathrm{PK}$, and $1 \mathrm{mM}$ DTT was incubated for $15 \mathrm{~min}$ at $30^{\circ} \mathrm{C}$ and then for $5 \mathrm{~min}$ at $0{ }^{\circ} \mathrm{C}$ in the absence $(\mathrm{A}, \mathrm{O} ; \mathrm{B}, \mathbf{\Delta} ; \mathrm{C}, \square ; \mathrm{D}, \boldsymbol{\bullet})$ or in the presence of $50 \mu \mathrm{M}$ kirromycin $(\diamond)$, pulvomycin $(\diamond)$, GE2270 A $(+)$, or enacyloxin IIA $(x)$. The dissociation reaction was initiated by the addition of a 1000-fold excess of unlabeled GTP. At the indicated times, aliquots $(40 \mu \mathrm{L})$ were withdrawn, and the EF-Tubound radioactivity was determined by the nitrocellulose binding assay.

Figure 9 show that this competition can take place with both mutants, in a remarkably similar manner. In fact, kirromycin and enacyloxin IIa were able to decrease to a comparable extent the stimulation by EF-Ts of the GDP dissociation rate from both $\operatorname{EF}-\mathrm{Tu}(\Delta \mathrm{M})$ and $\mathrm{EF}-\mathrm{Tu}(\Delta \mathrm{C})$. This shows that the two antibiotics can efficiently bind to the GDP-bound form of EF-Tu( $(\Delta \mathrm{M})$ despite the fact that its GTP-induced conformation was found to be near-irresponsive to their action.

\section{DISCUSSION}

The aim of this work was to fill the gap in our knowledge of the functions of domains 2 and 3 of EF-Tu, by engineering intermediary constructs between $\mathrm{G}$ domain and full-length EF-Tu. Since the G domain has nearly completely lost the ability to respond to the action of high molecular weight ligands or antibiotics (Parmeggiani et al., 1987), it was reasonable to assume that the two noncatalytic domains control the regulation of EF-Tu activities by ligands. Our results show that, despite the deletion of an entire noncatalytic domain, both mutated forms are still able to interact with GTP and GDP, as has been found for the G domain (Parmeggiani et al., 1987). They also catalyze the hydrolysis of GTP and can sustain the interactions with ligands, such 


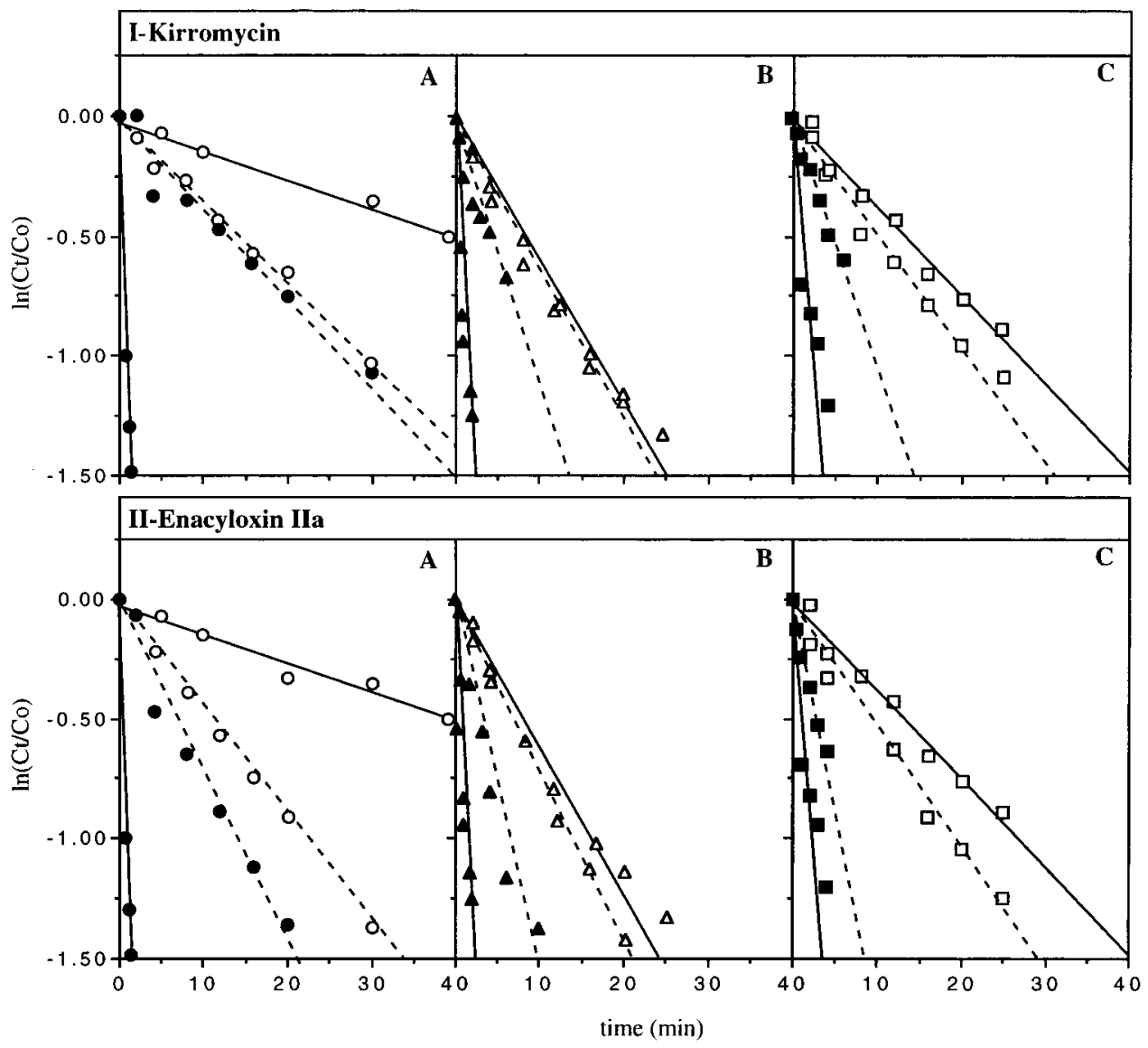

FIGURE 9: Kirromycin (I) and enacyloxin IIa (II) compete with EF-Ts for binding to EF-Tu( $\Delta C)$ and EF-Tu( $\Delta M)$. EF-Tu·GDP $(A)$, $\mathrm{EF}-\mathrm{Tu}(\Delta \mathrm{C})(\mathrm{B})$, or EF-Tu(M) $(\mathrm{C})(0.10 \mu \mathrm{M})$ was incubated in $400 \mu \mathrm{L}$ of standard buffer containing $0.12 \mu \mathrm{M}\left[{ }^{3} \mathrm{H}\right] \mathrm{GDP}$ (specific activity, $11000 \mathrm{dpm} / \mathrm{pmol}$ ) for $15 \mathrm{~min}$ at $30{ }^{\circ} \mathrm{C}$. After the additional incubation for $5 \mathrm{~min}$ at $0{ }^{\circ} \mathrm{C}$ in the presence of kirromycin or enacyloxin IIa (dashed lines) or in the absence of antibiotics (solid lines), with $0.01 \mu \mathrm{M}$ EF-Ts (closed symbols) or without EF-Ts (open symbols), the dissociation reaction was initiated by the addition of a 1000 -fold excess of cold GDP at $0{ }^{\circ} \mathrm{C}$. At the indicated times, aliquots $(40 \mu \mathrm{L})$ were withdrawn, and the EF-Tu-bound radioactivity was determined by the nitrocellulose binding assay.

as antibiotics and EF-Ts. The existence of a functionally active conformation and of selective properties dependent on whether the middle or the C-terminal domain is deleted supports the presence in both EF-Tu mutants of a folding close to that of the intact molecule. This agrees with NMR studies of Lowry et al. (1991) showing the conservation of an organized structural folding in the nucleotide binding region of the $\mathrm{G}$ domain even after removal of both noncatalytic domains. Also, the CD spectra of EF-Tu( $\Delta M)$ and EF$\operatorname{Tu}(\Delta \mathrm{C})$ indicate that the organization of the secondary structural elements of the two EF-Tu mutants is not dramatically changed. EF-Tu( $(\Delta \mathrm{M})$ displays a thermostability close to that of the intact molecule whereas $\mathrm{EF}-\mathrm{Tu}(\Delta \mathrm{C})$ resembles the $\mathrm{G}$ domain. It was important to verify whether the relative orientation of domains 1 and 3 in $\operatorname{EF}-\mathrm{Tu}(\Delta \mathrm{M})$ was not markedly altered. Therefore, in addition to functional tests we carried out a model building (Figure 10A) of the orientation and folding of these two domains after looping out residues 206-293. Using the 3D model of EF-TuGMPPNP from Thermus aquaticus (PDB database), we removed the residues from V217 (I206 in E. coli EF-Tu) to K306 (K294 in E. coli EF-Tu), after which energy minimization was applied. Our results show that the interaction forces between domains 1 and 3 of EF-Tu are strong enough to preserve the interface of these two domains, avoiding a significant displacement of the relative orientation and distance. Nor did we observe a significant difference in the folding of the two domains as shown by superimposition with the corresponding domains of the full-length EF-Tu. Another conclusion is that the resulting joining loop (11 residues between 201-205 and 294-299) connecting domain 1 (residues 4-200) and domain 3 (residues 300-393) after the deletion of the middle domain is long enough to span the distance between the two residual domains. Together, these observations show that all the individual domains of EF-Tu constitute remarkably stable conformational entities, capable of sustaining specific activities. This justifies their use, individually or in combination, to analyze the structural-functional relationships of EF-Tu in the interactions with ligands.

The affinities of EF-Tu( $\Delta \mathrm{C})$ and $\mathrm{EF}-\mathrm{Tu}(\Delta \mathrm{M})$ for GDP and GTP lie in the micromolar range and are comparable to those reported for the $\mathrm{G}$ domain (Parmeggiani et al., 1987). As has been shown for the $\mathrm{G}$ domain, the removal of either one of the two domains mainly influences the GDP-bound state of EF-Tu, decreasing the affinity for this nucleotide $\sim 1000$ times. These results suggest that the nucleotide binding pocket in the two mutants, independently of the presence of GTP or GDP, has an open conformation resembling that of EF-Tu GTP, whose affinity for the nucleotide is more than 100-fold less strong than for GDP. Thus, a typical feature of EF-Tu, the differential affinity for GTP and GDP, results from cooperative effects involving all three domains. Noteworthy, the half-life of the GDP complex of the two 

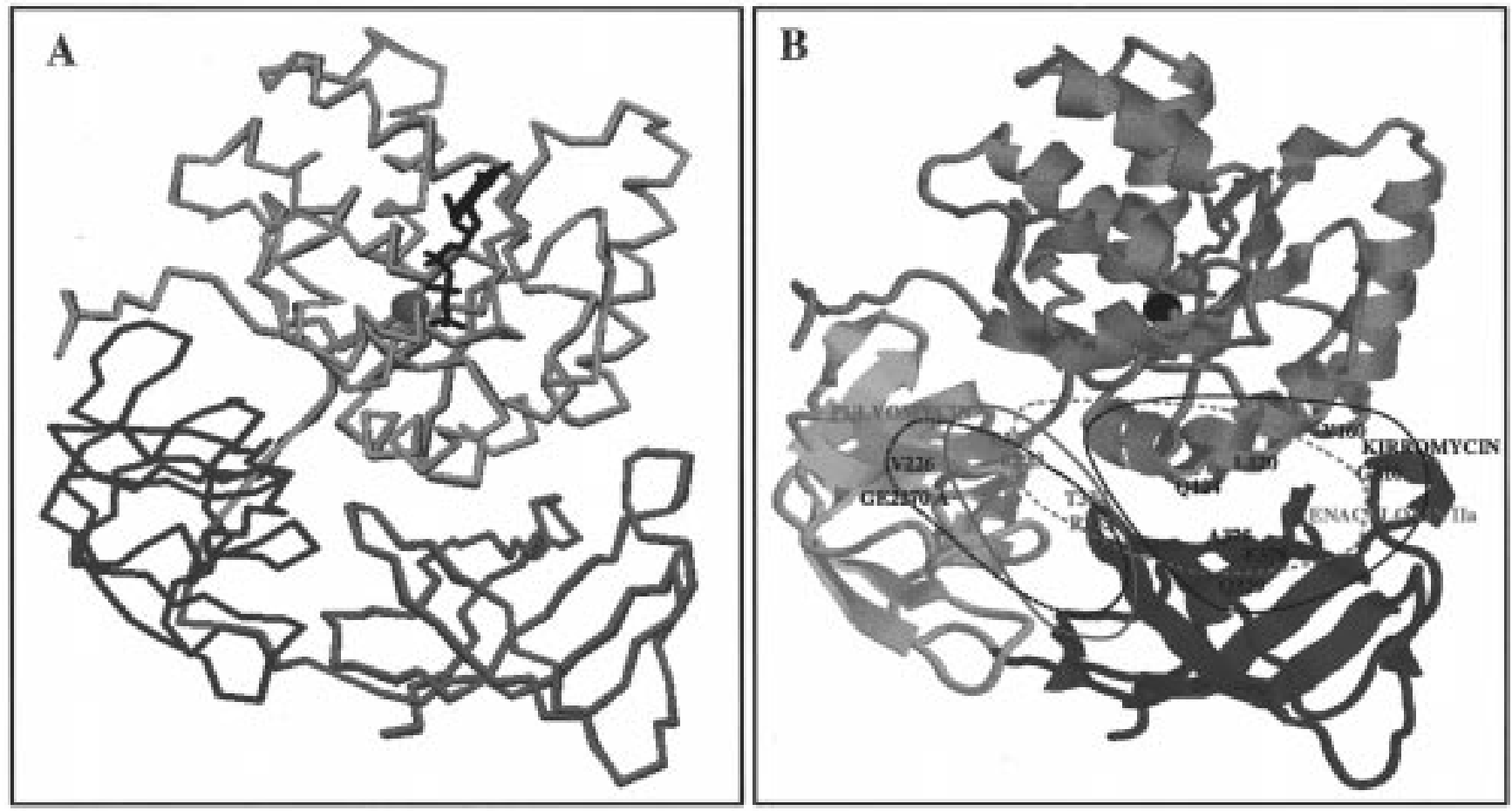

FIGURE 10: (A) The relative orientation of domains 1 and 3 is essentially conserved in the EF-Tu( $(\Delta \mathrm{M})$ construct. The coordinates of the T. aquaticus EF-Tu-GMPPNP model were obtained from the PDB database. Using a Quanta software package, residues V217-K306 (corresponding to I206 and K294, respectively, in E. coli EF-Tu) were removed, after which energy minimization was applied using the CHARMM22.0 force field. Color codes: full-length EF-Tu, blue; EF-Tu( $\Delta \mathrm{M}$ ), yellow (domain 1) and red (domain 3). (B) A model outlining possible regions of EF-Tu•GTP involved in the binding sites for antibiotics. This schematic representation has been derived from (i) comparative analyses of the actions of the antibiotics, (ii) the location of residues inducing resistance toward kirromycin (L120, Q124, Y160, G316, Q329, A375, and E378), pulvomycin (R230, R230/R233, R333, and T334), and possibly GE2270 A (V226, see Discussion), and (iii) the properties of the respective mutants. Pulvomycin and GE2270 A both abolish the interaction between EF-Tu and aa-tRNA taking place in the interfaces between domains 1 and 2 and domains 2 and 3; kirromycin and particularly enacyloxin IIa affect negatively the protection by EF-Tu of the aminoacylated N-terminal end of tRNA. Only kirromycin can enhance significantly the intrinsic GTPase activity of EF-Tu.

constructs is intermediary between that of the G-domain and of the intact molecule, suggesting a stabilization effect by each of the two noncatalytic domains. In the case of EF$\mathrm{Tu}(\Delta \mathrm{M})$, this can be rationalized in terms of the 3D model, where domain 3 appears to stabilize $\alpha$-helices B and C in the $\mathrm{N}$-terminal domain.

The intrinsic GTPase activity of $\mathrm{EF}-\mathrm{Tu}(\Delta \mathrm{M})$ was found to be similar to that of wild-type EF-Tu; that of EF-Tu( $(\Delta \mathrm{C})$ slightly decreased. Also, the stimulation by kirromycin is still present, though it is lower particularly in the case of deletion of the middle domain.

No stimulatory effect by ribosomes was observed on the intrinsic GTPase activity of the two mutated EF-Tu's. This was rather surprising, because ribosomes can slightly enhance the GTPase activity of the G domain (Parmeggiani et al., 1987; Jensen et al., 1989). The lack of an effect may be related to negative long-range changes induced by the residual noncatalytic domain on domain 1 .

Either one of the mutated forms can form a stable complex with aa-tRNA but only to an extent $<10 \%$ that of EF-Tu, whereas no binding of aa-tRNA can take place on the $G$ domain (Parmeggiani et al., 1987). These findings emphasize the importance of all three domains for an efficient binding of aa-tRNA. Cross-linking and protection studies suggested that the aminoacylated CCA 3 '-end of tRNA interacts with domains 1 and 2 (Jonák et al., 1980, 1984; Metz-Boutigue et al., 1989; Van Noort et al., 1984). The 3D model of Phe-tRNA ${ }^{\text {Phe }}$-bound T. aquaticus EF-Tu-
GppNHp (Nissen et al., 1995) shows that the binding site of the aminoacylated acceptor helix of tRNA is located in the interfaces of the three domains. The combination of $E$. coli (Pieper et al., 1990) or T. thermophilus (Peter et al., 1990) middle and C-terminal domains was unable to interact with aa-tRNA. For poly(Phe) synthesis, our results show that both noncatalytic domains of EF-Tu are required, as expected from the complexity of this process involving multiple steps and the formation of highly selective complexes.

A major result of this study was the finding that EF-Ts can stimulate efficiently to a comparable extent the release of GDP from both mutated constructs. Observation based on point substitutions (Hwang et al., 1992) suggested that the region of domain 1 comprising residues 154-195 interacts with EF-Ts. Peter et al. (1990) reported that the two noncatalytic domains interact with EF-Ts, since EF-Ts could retard the electrophoretic mobility of $T$. thermophilus EF-Tu lacking domain 1. The elucidation of the 3D structure of EF-Tu-EF-Ts (Kawashima et al., 1996) shows that the most extensive contact between the two proteins takes place on domain 1. Several structures are involved, such as the phosphate binding loop, the amino terminus of helix B-tightly associated with domain 3-and the helices $\mathrm{C}$ and D. Besides domain 1, only the tip of domain 3 appears to interact directly with EF-Ts. The observation that at least one noncatalytic domain is required for a productive interaction between EF$\mathrm{Tu}$ and EF-Ts indicates that both noncatalytic domains are 
involved in inducing the active conformation of domain 1 responsive to EF-Ts. In fact, the G domain-GDP complex shows an intrinsic dissociation activity much higher than that of EF-Tu $(\Delta \mathrm{C})$ and $\mathrm{EF}-\mathrm{Tu}(\Delta \mathrm{M})(c f$. Figure 7, panel D with panels $\mathrm{B}$ and $\mathrm{C}$ ). A regulatory indirect function of domain 2 is supported by the absence in the 3D model of contacts between this domain and EF-Ts (Kawashima et al., 1996). The physiological nature of the response to EF-Ts of the two mutated EF-Tu forms is further supported by the partial inhibition by kirromycin and enacyloxin IIa of the GDP release induced by EF-Ts, a specific effect typical for fulllength EF-Tu.

The observation that EF-Ts is unable to enhance the dissociation of the GTP complex of the mutants suggests that the differential affinity of EF-Ts for the GTP- and GDPbound forms of the constructs has become much larger than that of EF-Tu wild type. Indeed, the dissociation rate of EF-Tu $\cdot$ GTP is a few times less sensitive to EF-Ts than EFTu·GDP (Fasano et al., 1978).

Selective effects have been found in this work, as to the action of antibiotics on the two mutated EF-Tu's. EF-Tu$(\Delta \mathrm{C}) \cdot \mathrm{GTP}$ was much more responsive than $\mathrm{EF}-\mathrm{Tu}(\Delta \mathrm{M}) \cdot \mathrm{GTP}$ to all four EF-Tu-specific antibiotics, showing a response of the same kind as the full-length molecule. Site-directed mutagenesis has shown that the substitutions conferring kirromycin resistance concern residues L120, Q124, and Y160 on domain 1 and G316, Q329, E378, T357, and A375 on domain 3 (Parmeggiani \& Swart, 1985; Mesters et al., 1994; Abdulkarim et al., 1994). Functional and structural analyses have led to the conclusion that the interface of domain 1 with domain 3 , whose extention is markedly different in the GDP- and GTP-bound forms of EF-Tu, harbors the binding site for kirromycin, very likely involving Q124 (Mesters et al., 1994). Our results show that even after removal of domain 3 kirromycin can still interact with EF-Tu, with an efficiency stronger than after removal of domain 2. Hence, the presence of domain 2 is crucial for inducing an active binding site for kirromycin on domain 1 . Moreover, the inhibition of the action of EF-Ts on EF-Tu$(\Delta \mathrm{M}) \cdot \mathrm{GDP}$ shows that kirromycin can tightly bind to domain 1 in the absence of domain 2. One can conclude that the two noncatalytic domains act by concurring directly (domain 3 ) or indirectly (domain 2) to the activation of the kirromycin binding site on domain 1 . The ability of $\operatorname{EF}-\mathrm{Tu}(\Delta \mathrm{M}) \cdot \mathrm{GDP}$ to support specific effects such as the action of EF-Ts and the response to kirromycin and enacyloxin IIa shows that the selective properties of the two mutated constructs are a consequence of the removal of specific structures and not the result of an unspecific conformational disorder. Additional information on the role of both noncatalytic domains in the interaction of EF-Tu with kirromycin might become available soon, since the complex EF-Tu kirromycin has been crystallized recently (Kristensen et al., 1996).

Although enacyloxin IIa-resistant mutants of EF-Tu have as yet to be isolated, the similarities of its action on EF-Tu and EF-Tu EF-Ts to that of kirromycin suggest that its binding site also involves the interface between domains 1 and 3 and is likely situated on domain 1 . The location of the binding sites for kirromycin and enacyloxin IIa in a domain interface could explain the ability of the two antibiotics to deregulate all the interactions between EF-Tu and the various ligands by modifying the relative orientation of two domains and thus of the overall conformation of the molecule.

The residues, whose substitution induces pulvomycin resistance (R230 and R230/R233 on domain 2, R333 and T334 on domain 3; Zeef et al., 1994; Boon et al., 1995), are located in the interfaces of the three domains of EF-Tu. Even though structural considerations make uncertain that these residues are part of the binding site for pulvomycin (Zeef et al., 1995), the lack of response of EF-Tu( $(\Delta \mathrm{M})$ to pulvomycin and the probable existence of distinct binding sites for pulvomycin and kirromycin (Pingoud et al., 1982) and of hindrance phenomena between aa-tRNA and pulvomycin appear to favor a location of the binding site for pulvomycin close to the domain 2/domain 3 interface.

Shimanaka et al. (1995) have isolated Bacillus subtilis EFTu mutated in V228A (corresponding to V226 in E. coli EF$\mathrm{Tu}$ ) resistant to amythiamicin, an antibiotic whose structure is closely related to GE2270 A. We have found that GE2270 A efficiently retards the dissociation rate of $\operatorname{EF}-\mathrm{Tu}(\Delta \mathrm{C}) \cdot \mathrm{GTP}$, without affecting that of EF-Tu( $\Delta \mathrm{M})$, like pulvomycin, and have also observed that GE2270 A induces a band shift of $\mathrm{EF}-\mathrm{Tu}(\Delta \mathrm{C})$ during nondenaturing PAGE (P. H. Anborgh, unpublished observations). These results, together with the similarity of its action with that of pulvomycin, suggest that the GE2270 A binding site also involves the middle and C-terminal domain of EF-Tu.

Figure 10B illustrates the probable locations on EF-TuGTP of the binding sites for antibiotics, as derived from our present knowledge of the properties of EF-Tu mutants.

When this work was in progress, Nock et al. (1995) described the properties of $T$. thermophilus EF-Tu lacking domain 3. This construct showed a similar affinity for GDP and GTP, like the corresponding G domain and our E. coli $\operatorname{EF}-\operatorname{Tu}(\Delta C)$. The presence of domain 2 increased the thermostability of $T$. thermophilus domain 1 and even more markedly the intrinsic GTPase activity of this domain, two effects that we could not observe with $E$. coli $\operatorname{EF}-\mathrm{Tu}(\Delta \mathrm{C})$. Moreover, $T$. thermophilus EF-Ts was inactive on $T$. thermophilus EF-Tu(I, II). At present, it is not possible to explain these differences that may be, at least in part, related to the intrinsic properties of $T$. thermophilus EF-Tu and EFTs or the specific experimental conditions used.

In conclusion, our work outlines selective effects on domains 2 and 3 of EF-Tu in the action of antibiotics and EF-Ts and emphasizes their cooperative function in the interaction with ribosomes and aa-tRNA and in the differential affinity for GTP and GDP. The removal of either one of the noncatalytic domains has revealed effects, whose structural background is not always clear. In fact, in the 3D model only domain 3 interacts with EF-Ts; however, EF$\mathrm{Tu}(\Delta \mathrm{C})$ induces a functional response to EF-Ts as EF-Tu$(\Delta \mathrm{M})$ and EF-Tu wt, unlike the isolated domain $1 \mathrm{EF}-$ $\mathrm{Tu}(\Delta \mathrm{C})$ responds to kirromycin more efficiently than EF$\mathrm{Tu}(\Delta \mathrm{M})$ though the binding of the antibiotic is very likely situated in the domain 1/domain 3 interface. These results support the existence of long-range effects that cannot yet be explained by the static configuration of the to date $3 \mathrm{D}$ models and suggest caution in interpreting functional observations on the basis of our present structural knowledge. 


\section{ACKNOWLEDGMENT}

We are grateful to Drs. Ivo M. Krab and Maria Carla Parrini for discussions and critical reading of the manuscript, to Rob te Biesebeke for technical assistance, and to Dr. JeanBernard Créchet for advice. We are indebted to Dr. Frédéric Dardel for the model building of EF-Tu( $\Delta \mathrm{M})$.

\section{REFERENCES}

Abdulkarim, E., Liljas, J., \& Hughes, D. (1994) FEBS Lett. 352, 118-122.

Abel, K., Yoder, M. D., Hilgenfeld, R., \& Jurnak, F. (1996) Structure 4, 1153-1159.

Anborgh, P. H., \& Parmeggiani, A. (1991) EMBO J. 10, 779784.

Anborgh, P. H., \& Parmeggiani, A. (1993) J. Biol. Chem. 268, 24622-24628.

Anborgh, P. H., Swart, G. W. M., \& Parmeggiani, A. (1991) FEBS Lett. 292, 232-236.

Berchtold, H., Reshetnikova, L., Reiser, C. O. A., Schirmer, N., Sprinzl, M., \& Hilgenfeld, R. (1993) Nature 365, 126-132.

Boon, K., Krab, I., Parmeggiani, A., Bosch, L., \& Kraal, B. (1995) Eur. J. Biochem. 227, 816-822.

Bradford, M. M. (1976) Anal. Biochem. 72, 248-254.

Cetin, R., Krab, I. M., Anborgh, P. H., Cool, R. H., Watanabe, T., Sugiyama, T., Izaki, K., \& Parmeggiani, A. (1996) EMBO J. $15,2604-2611$.

Créchet, J.-B., \& Parmeggiani, A. (1986) Eur. J. Biochem. 161, 647-653.

Fasano, O., Bruns, W., Créchet, J. B., Sander, G., \& Parmeggiani, A. (1978) Eur. J. Biochem. 89, 557-565.

Fasano, O., De Vendittis, E., \& Parmeggiani, A. (1982) J. Biol. Chem. 257, 3145-3150.

Hwang, Y.-W.; Carter, M., \& Miller, D. (1992) J. Biol. Chem. 267, 22198-22205.

Ivell, R., Sander, G., \& Parmeggiani, A. (1981) Biochemistry 20, 6852-6859.

Jacquet, E., \& Parmeggiani, A. (1988) EMBO J. 7, 2861-2867.

Jensen, M., Cool, R. H., Mortensen, K. K., Clark, B. F. C., \& Parmeggiani, A. (1989) Eur. J. Biochem. 182, 247-255.

Jonák, J., Smrt, J., Holy, A., \& Rychlík, I. (1980) Eur. J. Biochem. 105, 315-320.

Jonák, J., Petersen, T. E., Meloun, B., \& Rychlík, I. (1984) Eur. J. Biochem. 144, 295-303.

Jurnak, F. (1985) Science 230, 32-36.

Kawashima, T., Berthet-Colominas, C., Wulff, M., Cusack, S., \& Leberman, R. (1996) Nature 379, 511-518.

Kaziro, Y. (1978) Biochim. Biophys. Acta 505, 95-127.

Kjeldgaard, M., \& Nyborg, J. (1992) J. Mol. Biol. 223, 721-742.

Kjeldgaard, M., Nissen, P., Thirup, S., \& Nyborg, J. (1993) Structure 1, 35-50.
Kristensen, O., Reshetnikova, L., Nissen, P., Sibosk, G., Thirup, S., \& Nyborg, J. (1962) FEBS Lett. 399, 59-62.

Lowry, D. F., Cool, R. H., Redfield, A. G., \& Parmeggiani, A. (1991) Biochemistry 30, 10871-10877.

Mesters, J. R., Zeef, L. A. H., Hilgenfeld, R., de Graaf, J. M., Kraal, B., \& Bosch, L. (1994) EMBO J. 13, 4877-4855.

Metz-Boutigue, M.-H., Reinboldt, J., Ebel, J.-P., Ehresmann, C., \& Ehresmann, B. (1989) FEBS Lett. 245, 194-199.

Miller, D. L., \& Weissbach, H. (1977) Molecular Mechanisms of Protein Biosynthesis (Weissbach, H., \& Pestka, S., Eds.) pp 323373, Academic Press, New York.

Nissen, P., Kjeldgaard, M., Thirup, S., Polekhina, G., Reshetnikova, L., Clark, B. F. C., \& Nyborg, J. (1995) Science 270, 14641472.

Nock, S., Grillenbeck, N., Ahmadian, M. R., Kreutzer, R., \& Sprinzl, M. (1995) Eur. J. Biochem. 234, 132-139.

Parmeggiani, A., \& Sander, G. (1981) Mol. Cell. Biochem. 35, 129158.

Parmeggiani, A., \& Swart, G. W. M. (1985) Annu. Rev. Microbiol. 39, 557-577.

Parmeggiani, A., Swart, G. W. M., Mortensen, K. K., Jensen, M., Clark, B. F. C., Dente, L., \& Cortese, R. (1987) Proc. Natl. Acad. Sci. U.S.A. 84, 1814-1818.

Peter, M. E., Reiser, C. O. A., Schirmer, N. K., Kiefhaber, T., Ott, G., Grillenbeck, N. W., \& Sprinzl, M. (1990) Nucleic Acids Res. 18, 6889-6893.

Pieper, U., Ehbrecht, H. J., Fliess, A., Schick, B., Jurnak, F., \& Pingoud, A. (1990) Biochim. Biophys. Acta 1087, 147-156.

Pingoud, A., Block, W., Urbanke, W., \& Wolf, H. (1982) Eur. J. Biochem. 123, 261-265.

Polekhina, G. Thirup, S., Kjeldgaard, M., Nissen, P., Lippmann, C., \& Nyborg, J. (1996) Structure 4, 1141-1151.

Sambrook, J., Fritsch, E. F., \& Maniatis, T. (1989) in Molecular Cloning, a Laboratory Manual, 2nd ed., Cold Spring Harbor Laboratory Press, Cold Spring Harbor, NY.

Scarano, G., Krab, I., Bocchini, V., \& Parmeggiani, A. (1995) FEBS Lett. 365, 214-218.

Shimanaka, K., Iinuma, H., Hamada, M., Ikeno, S., Tsuchiya, K. S., Arita, M., \& Hori, M. (1995) J. Antibiot. 48, 182-184.

Smith, D. B., \& Johnson, K. S. (1988) Gene 67, 31-40.

Swart, G. W. M., Parmeggiani, A., Kraal, B., \& Bosch, L. (1987) Biochemistry 26, 2047-2054.

Van Noort, J. M., Kraal, B., Bosch, L., la Cour, T. F. M., Nyborg, J., \& Clark, B. F. C. (1984) Proc. Natl. Acad. Sci. U.S.A. 81, 3969-3972.

Weijland, A., Harmark, K., Cool, R. H., Anborgh, P. H., \& Parmeggiani, A. (1992) Mol. Microbiol. 6, 683-688.

Zeef, L. A. H., Bosch, L., Anborgh, P. H., Cetin, R., Parmeggiani, A., \& Hilgenfeld, R. (1994) EMBO J. 13, 5113-5120.

BI970443O 